\title{
Nanoscale click-reactive scaffolds from peptide self-assembly
}

\author{
Alexander P. M. Guttenplan 1,20, Laurence J. Young ${ }^{3}$, Dijana Matak-Vinkovic ${ }^{2}$, Clemens F. Kaminskiº, \\ Tuomas P. J. Knowles ${ }^{2^{*}}$ and Laura S. Itzhaki ${ }^{1^{*}}$ (D)
}

\begin{abstract}
Background: Due to their natural tendency to self-assemble, proteins and peptides are important components for organic nanotechnology. One particular class of peptides of recent interest is those that form amyloid fibrils, as this self-assembly results in extremely strong, stable quasi-one-dimensional structures which can be used to organise a wide range of cargo species including proteins and oligonucleotides. However, assembly of peptides already conjugated to proteins is limited to cargo species that do not interfere sterically with the assembly process or misfold under the harsh conditions often used for assembly. Therefore, a general method is needed to conjugate proteins and other molecules to amyloid fibrils after the fibrils have self-assembled.
\end{abstract}

Results: Here we have designed an amyloidogenic peptide based on the TTR105-115 fragment of transthyretin to form fibrils that display an alkyne functionality, important for bioorthogonal chemical reactions, on their surface. The fibrils were formed and reacted both with an azide-containing amino acid and with an azide-functionalised dye by the Huisgen cycloaddition, one of the class of "click" reactions. Mass spectrometry and total internal reflection fluorescence optical microscopy were used to show that peptides incorporated into the fibrils reacted with the azide while maintaining the structure of the fibril. These click-functionalised amyloid fibrils have a variety of potential uses in materials and as scaffolds for bionanotechnology.

Discussion: Although previous studies have produced peptides that can both form amyloid fibrils and undergo "click"-type reactions, this is the first example of amyloid fibrils that can undergo such a reaction after they have been formed. Our approach has the advantage that self-assembly takes place before click functionalization rather than pre-functionalised building blocks self-assembling. Therefore, the molecules used to functionalise the fibril do not themselves have to be exposed to harsh, amyloid-forming conditions. This means that a wider range of proteins can be used as ligands in this process. For instance, the fibrils can be functionalised with a green fluorescent protein that retains its fluorescence after it is attached to the fibrils, whereas this protein loses its fluorescence if it is exposed to the conditions used for aggregation.

Keywords: Amyloid fibrils, Click reactions, Bioconjugation, Super-resolution microscopy, Self-assembly, Bionanotechnology

\section{Background}

Peptide self-assembly has emerged as an attractive route towards organic nanotechnology. Such self-assembled

\footnotetext{
*Correspondence: tpjk2@cam.ac.uk; Isi10@cam.ac.uk

${ }^{1}$ Department of Pharmacology, University of Cambridge, Tennis Court Road, Cambridge CB2 1PD, UK

${ }^{2}$ Department of Chemistry, University of Cambridge, Lensfield Road, Cambridge CB2 1EW, UK

Full list of author information is available at the end of the article
}

designed biomaterials have found a range of uses from templating nano- and microscale electronics to acting as scaffolds for cell culture or tissue engineering [1-3]. A particularly simple yet general form of peptide and protein self-assembly is that leading to linear, homomolecular structures; in many cases, the component peptides within these nanostructures are held together with a backbone-backbone hydrogen bonding network that leads to extended $\beta$-sheets running along the fibril axis 
$[4,5]$. Such $\beta$-sheet-rich amyloid or amyloid-like fibrils are recognised for their biological roles both in diseases such as Alzheimer's and Parkinson's [6, 7] and as functional components in some organisms [8-11].

More recently, amyloid fibrils have been explored as potential materials for use in nanotechnology applications. One reason for this interest is their robust mechanical strength and rigidity, which have some of the highest values known for biological systems [12-14]. In addition, the fact that fibrils self-assemble has led to research into making them functional, for example as electrically conducting nanowires $[15,16]$, for carbon capture [17] or as drug carriers [18]. However, introducing chemical functionality to these self-assembled biomaterials has hitherto often required the material to self-assemble from components that already include the functional moiety. In this approach, the choice of functionality is limited to species that can survive the conditions of self-assembly with their function intact and that do not themselves disturb it [19]. Here, we address this limitation with a new method, which allows the fibrils to be functionalized after they are formed using mild conditions that tolerate a wide range of substrates. We show that this approach allows even sensitive proteins which are not compatible with the selfassembly conditions to be used as the cargo and that this strategy thus significantly extends the chemical space of available for selecting species that can be organized on the nanoscale through peptide self-assembly. Moreover, the strategy is highly adaptable with the potential for proteins to be attached to fibrils via a non-natural amino acid inserted at any position in the protein (using a variety of methods $[20,21]$ ) or for the same protein molecule to be attached to multiple fibrils, in contrast with existing methods where the protein can only be attached at one terminus [22]. Our approach will allow the amyloid fibrils to be linked together by proteins so that a force exerted on the amyloid fibrils, for instance by deformation of an amyloid-based material [13, 23], is transmitted to the protein as both termini of the protein are connected to the fibril rather than one being free. This would allow force-responsive proteins to be incorporated in an amyloid-based material for soft nanotechnology applications. Also, it means that proteins can be conjugated to fibrils at a different position in cases where terminal conjugation would inhibit the function of the protein.

To demonstrate the general nature of our approach, we generated a nanoscale scaffold capable of capturing a wide range of functional molecules, including folded proteins and small molecules, to pre-assembled fibrils. We exploited the Huisgen cycloaddition [24], one of the class of "click" chemical reactions defined by Sharpless et al. [25] which have a wide range of applications in bioconjugation [26]. In addition to the defining features of a "click" reaction-proceeding to completion in water at relatively low temperatures without side products-the Huisgen reaction is completely bioorthogonal, as it takes place between functional groups that do not exist in natural biomolecules [27]. Therefore, it can be used to selectively link together biomolecules into which the reactive functional groups have been introduced.

This reaction has previously been used to produce amyloid or other beta-sheet-rich fibrils functionalized with oligonucleotides [28] or polymers [29]. However, in both of these cases the cycloaddition reaction was performed on the peptide monomers, which were then allowed to aggregate to form the fibril. To the best of our knowledge the present work represents the first example of a "click" reaction being performed on an amyloid fibril after it has been formed (Fig. 1). Crucially, functionalizing the nanofibrils after they have been formed rather than before means that the species used to functionalize them need not be exposed to aggregation-promoting conditions. This approach thus has the important advantage of allowing a greater range of species, particularly proteins, to be used to functionalize amyloid fibrils, as proteins can be used that would otherwise denature and form aggregates under the conditions in which the fibrils form.

The amyloid-forming peptide used here was based on the well-characterized TTR105-115 peptide [30], which is a fragment of the human plasma protein transthyretin-itself a protein that forms amyloid associated with diseases such as familial amyloid polyneuropathy [31]. Fibrils formed from the TTR105-115 fragment are, however, non-toxic and biocompatible and have been explored for tissue culture applications [32]. The TTR105-115 fragment is known to form amyloid fibrils which can display chemical functionality at the $\mathrm{N}$-terminal end of the peptide on their surface [32]. The peptide was chosen because it is short enough to synthesize easily by solid-phase peptide synthesis. This method allows the incorporation of almost any chemical functionality via non-natural amino acids, as the amino acids used need not be viable substrates for ribosomal protein synthesis. However, it is long enough that the amyloidogenic part of the peptide is significantly larger than the non-amyloidogenic part used to add click functionality. The latter consists of a 3-glycine linker followed by $O$-propargyl serine-an alkyne-containing amino acid chosen for ease of synthesis.

\section{Results}

\section{Synthesis of fibrils}

We first carried out self-assembly of the TTR105-115 peptides into nanoscale fibrils and examined their morphology using atomic force microscopy. The micrographs show that their morphology and dimensions 


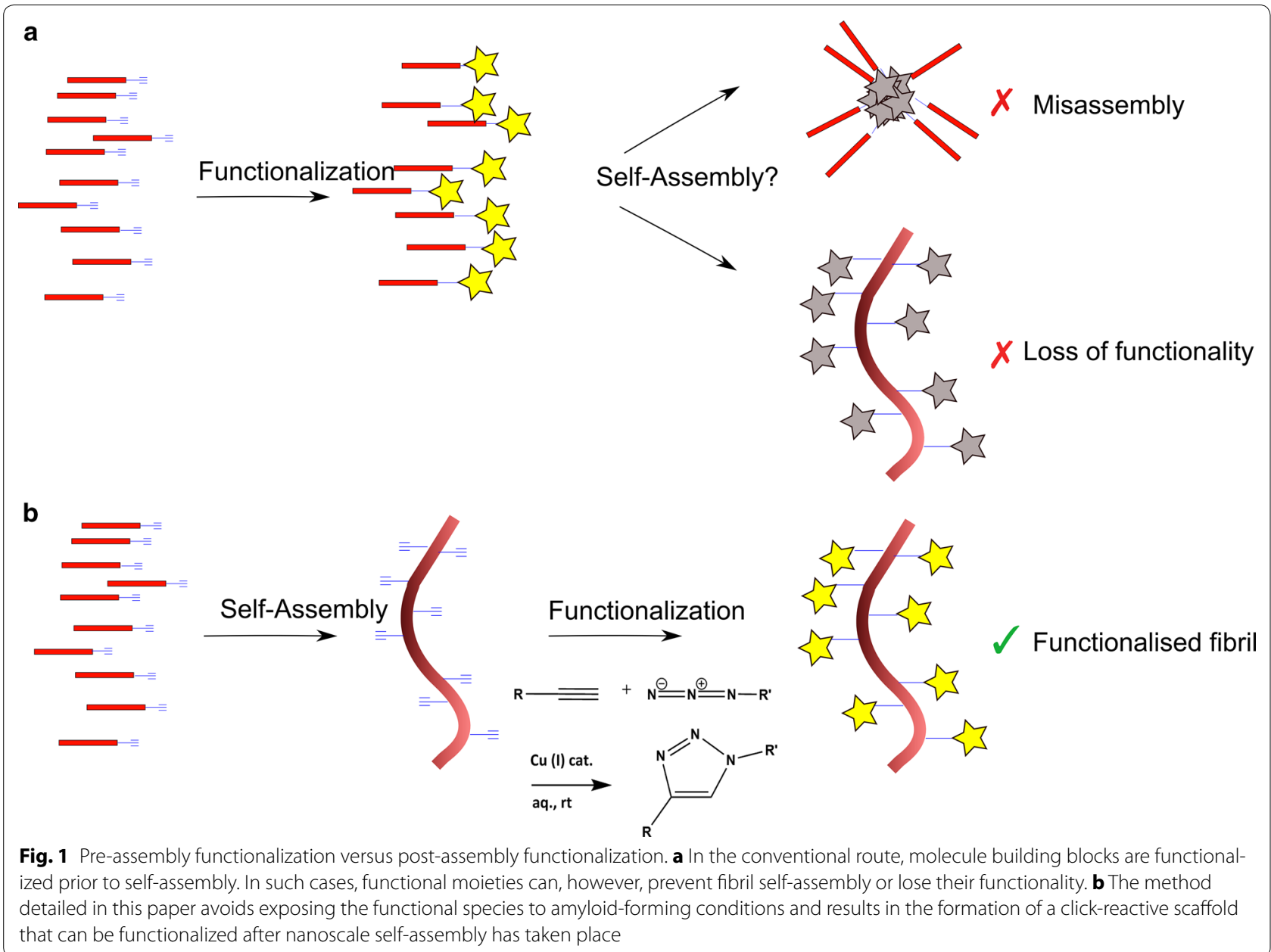

corresponded to that seen in the literature for TTR105115 amyloid fibrils, being fairly straight fibrils with a length of several $\mu \mathrm{m}$ and a height of $6-8 \mathrm{~nm}$. Figure 2 inset [12].

\section{Azidohomoalanine click experiments}

In order to demonstrate the click reactivity of the selfassembled nanostructures, we exposed the fibrils to azidohomoalanine and isolated the nanostructures from any soluble material by means of ultracentrifugation. The fibrils were then denatured and the released peptides subjected to mass spectrometry analysis. The mass spectrum of the fibrils (Fig. 2) reacted with azidohomoalanine gave a peak at an $m / z$ value of 1637.87 , which corresponds to the calculated mass of the "clicked" adduct with azidohomoalanine. The major peak, at $m / z=1515.79$, corresponds to the loss of the $\mathrm{N}$-terminal tyrosine from this adduct, and the peak at 1531.76 corresponds to the loss of its sidechain. The peak at 1493.80 corresponds to unreacted peptide, either due to the reaction not going to completion or because the alkyne moieties in some of the peptide molecules were buried in the fibril and unable to react.

By contrast, fibrils made from the unfunctionalised 'wild-type' amide-terminated TTR105-115 peptide (sequence YTIAALLSPYS- $\mathrm{NH}_{2}$ ) did not react and the major peaks in their mass spectrum (Fig. 2) are at $m / z=1197.68$, corresponding to unreacted peptide, and at $m / z=1219.7$, corresponding to a sodium adduct. Note that the difference in $m / z$ value for this peak compared to that for unreacted TTR-A1 is due to the unfunctionalised TTR105-115 peptide lacking the unreacted amino acid and the triglycine linker.

\section{Fluorescein click experiments}

We next repeated the functionalization process with a fluorescein analogue containing an azide group. The visible yellow color of the pellet after ultracentrifugation of the fibrils suggested that they had reacted to form a fluorescein adduct. Total internal reflection fluorescence (TIRF) microscopy (Fig. 3) showed fluorescent fibrils, confirming that fluorescein was localized to the fibril 


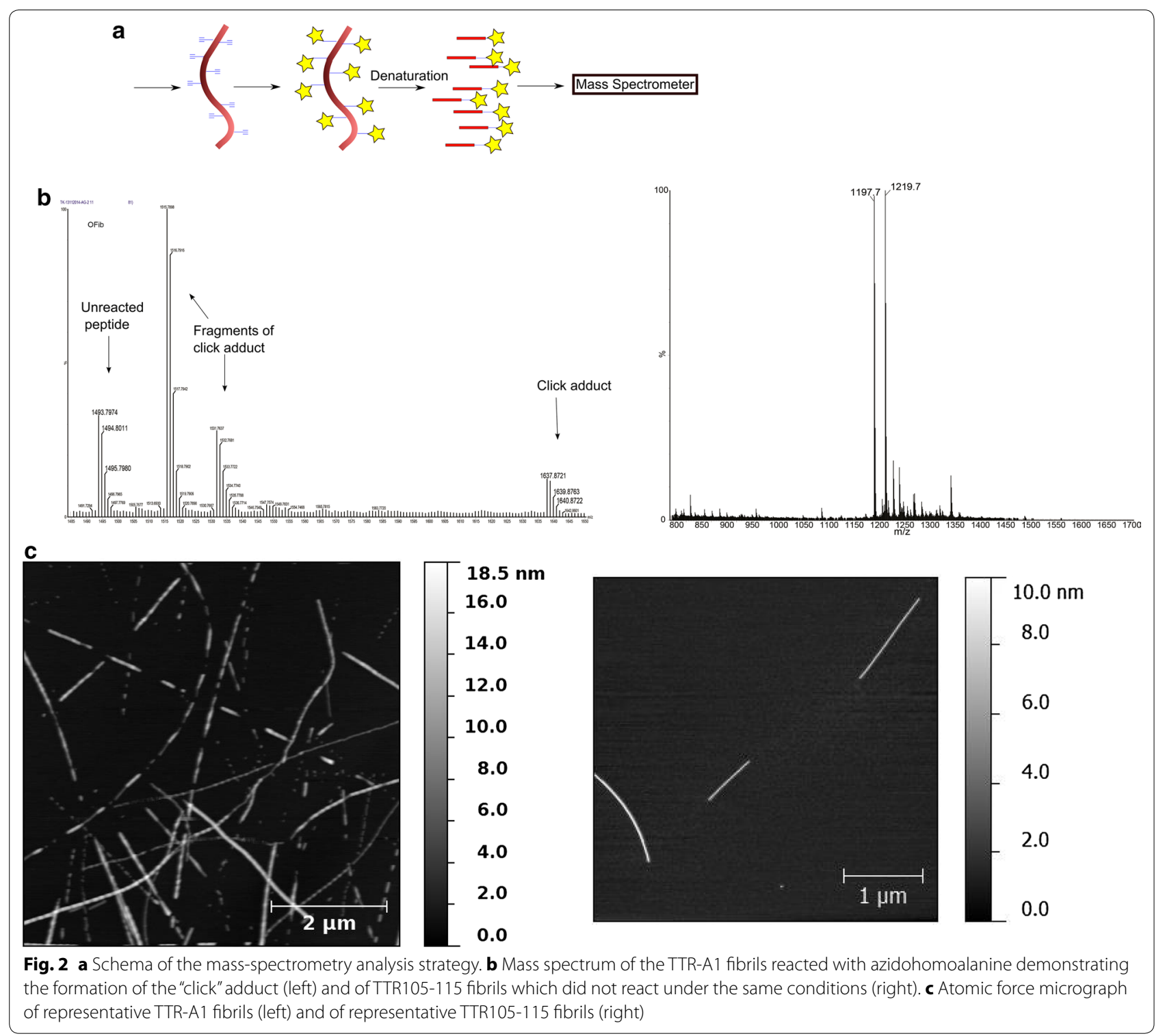

surface. This is due to a reaction between the alkyne functional groups on the peptide surface and the azide functionality on the fluorescein, resulting in fluoresceinfunctionalized and therefore visibly fluorescent amyloid fibrils.

\section{eGFP click experiments}

In order to demonstrate the generality of our approach, we finally focused on coupling entire proteins to the nano-scaffold. To this effect, we used enhanced Green Fluorescent Protein (eGFP) as the cargo species. There was visibly more eGFP in the supernatant of the control sample than in that of the clicked fibrils, suggesting that eGFP had successfully been conjugated to the fibrils.
Moreover, a visible precipitate had formed in the reaction mixture where aggregation took place after conjugation of eGFP to peptide. This reaction mixture was no longer fluorescent when exposed to UV light, whereas the clicked fibrils were (Fig. 3). Therefore, eGFP does not retain its fluorescence when exposed to the conditions of aggregation, possibly because it has itself aggregated.

TIRF micrographs show fluorescent fibrils (Fig. 3), whereas no fluorescent fibrils were visible in a "control" reaction carried out in the absence of copper sulfate and sodium ascorbate. The fluorescence polarization of eGFP that had reacted with fibrils was greater than that of free eGFP (Additional file 1: Figure S1). Although this difference is significant, it is smaller than might perhaps 


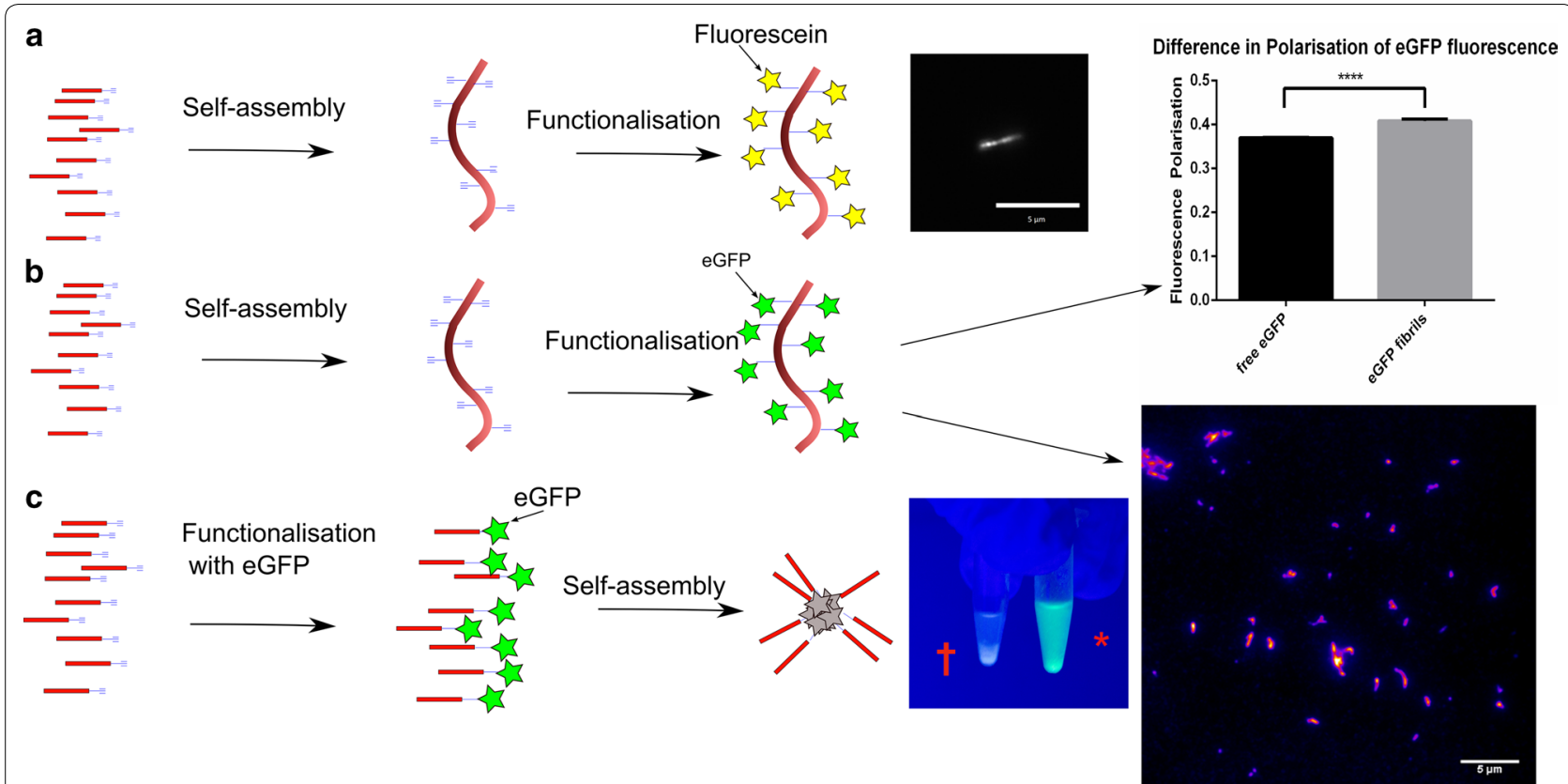

Fig. 3 Reaction of fibrils and peptides with eGFP and fluorescein. a Fibrils assemble and can then be functionalized with fluorescein to give fluorescent fibrils, as shown in TIRF image. Scale bar $5 \mu \mathrm{m}$. b Fibrils assemble and can then be functionalized with eGFP to give fluorescent fibrils ( + ) as shown in TIRF image. Scale bar $5 \mu \mathrm{m}$. c Peptides functionalized with eGFP form aggregates that are not fluorescent (*), as can be seen under UV illumination

be expected given the very large size of the fibrils. This observation can be rationalized by considering that there is a long flexible "tether" of approximately 23 amino acids (the-GGGX section of the peptide followed by the tag on the eGFP from the pOPIN_F vector) between the fibril and the eGFP, and the N-terminal region of eGFP is also flexible [33]. Therefore, even bound eGFP has a high enough degree of freedom of movement to exhibit some fluorescence depolarization.

\section{Conclusions}

In this paper, we have discussed and demonstrated a strategy to form nanoscale scaffolds that can be functionalized after their self-assembly has taken place. We showed that an approach that proceeds via click-reactive scaffolds allows a wide variety of molecular species to be used, including ones that are not compatible with the conditions required for self-assembly mediated nanoscale organization. We implemented this strategy using amyloid fibrils which were successfully formed from a peptide based on the TTR105-115 amyloidogenic sequence with the addition of a C-terminal alkyne functionality. The formed fibrils were shown to be capable of undergoing a "click" reaction with various azide-containing molecules, including proteins, which do not survive the conditions of fibril formation. These results open up the possibility of using amyloid scaffolds to organize a wide variety of cargo components, from small molecules to amino acids and proteins, for potential applications both in protein aggregation research and soft nanotechnology.

\section{Experimental methods}

Unless otherwise stated, all reagents were used as received without further purification. Fmoc-protected amino acids were obtained from Novabiochem (Darmstadt, Germany) or AGTC Bioproducts (Hessle, UK) except for Fmoc-O-propargyl serine, which was synthesized as described in the Additional file 1. Tris(3hydroxypropyltriazolylmethyl)amine (THPTA) was synthesized by Yu Heng Lau according to an established procedure [34].

\section{Peptide synthesis and fibril assembly}

The peptide TTR-A1, with sequence YTIAALLSPYSGGGX-NH $\mathrm{N}_{2}$ where $\mathrm{X}=\mathrm{O}$-propargyl serine, was synthesized on a CEM Liberty microwave peptide synthesizer (CEM Ltd., Buckingham, UK) on Rink amide resin (Novabiochem) according to standard Fmoc synthesis protocols [35] using HBTU as the activator and DIEA as the base. The peptide was manually cleaved from the resin using a 95:2.5:2.5 TFA:triisopropylsilane:water cleavage cocktail, precipitated with ether, and purified by HPLC on an Agilent 1260 Infinity system (Agilent, 
Stockport, UK) using a linear acetonitrile:water gradient before being lyophilized.

To induce fibril assembly, the lyophilized peptide was dissolved in a $10 \%$ solution of acetonitrile in water at a concentration of $10 \mathrm{mg} / \mathrm{mL}$ and incubated in a sonication bath to aid dissolution. This solution was then shaken at $600 \mathrm{rpm}$ at $37^{\circ} \mathrm{C}$ for $24 \mathrm{~h}$ to give a suspension of fibrils which were imaged by atomic force microscopy (AFM).

\section{Atomic force microscopy}

Fibrils were diluted in milliQ water to yield a suspension with a final peptide concentration of $0.01-0.05 \mathrm{mg} / \mathrm{mL}$. A $30 \mu \mathrm{L}$ aliquot of the resulting diluted suspension was deposited onto a freshly cleaved mica surface and allowed to dry in air before being imaged using a JPK Nanowizard III AFM (JPK Instruments AG, Berlin, Germany) in intermittent contact mode with an uncoated HQ:NSC36 tip (MikroMasch, Wetzlar, Germany). Images were flattened, levelled and height medians of lines matched using standard techniques and the Gwyddion software [36].

\section{Click reaction with azidohomoalanine}

The Huisgen reaction is a 1,3-dipolar cycloaddition reaction between an azide and a terminal alkyne to give a 1,2,3-triazole. The reaction is extremely regioselective, giving the 1,4-substituted triazole exclusively, and will tolerate a wide range of functional groups. The catalytic species is $\mathrm{Cu}(\mathrm{I})$, which is usually produced in situ by the reduction of a $\mathrm{Cu}$ (II) salt [37]. Fibrils were reacted with azidohomoalanine (Iris Biotech $\mathrm{GmbH}$, Marktredwitz, Germany) using an adapted version of the method of Presolski et al. [38]. Azidohomoalanine hydrochloride (1.4 mM), TTR-A1 fibrils $(1 \mathrm{mg} / \mathrm{mL}, 700 \mu \mathrm{M}$ monomer equivalent), copper(II) sulfate $(0.2 \mathrm{mM})$, THPTA (1 mM) and sodium ascorbate $(10 \mathrm{mM})$ were dissolved in water $(0.5 \mathrm{~mL})$. All reagents were added as concentrated stock solutions in water-the copper(II) sulfate and THPTA were mixed before being added, and the sodium ascorbate added last. The reaction mixture was placed in a closed tube and shaken at room temperature for $24 \mathrm{~h}$.

A $200 \mu \mathrm{L}$ aliquot of the reaction mixture was ultra centrifuged at $313,000 \times g$ for 30 min using a TLA-100 rotor (Beckman Coulter, High Wycombe, UK) to isolate the fibrils. The supernatant, containing any unaggregated monomer, was removed by pipetting and the fibrils resuspended in $200 \mu \mathrm{L}$ water. The resuspended fibrils were analyzed by liquid chromatography mass spectrometry (LC-MS) on a Waters Xevo G2-S instrument (Waters, Manchester, UK) using a C18 column. MS experiments were performed at a capillary voltage of $1900 \mathrm{~V}$, cone voltage of $80 \mathrm{~V}$ and source offset voltage of $80 \mathrm{~V}$. Spectra were processed using MassLynx V4.1 (Waters).

\section{Click reaction with fluorescein}

Fibrils were reacted with 5-fluorescein amidite azide (FAM-5 azide, Lumiprobe, Hannover, Germany) $(50 \mu \mathrm{M})$ using the same method as above. Again, a $200 \mu \mathrm{L}$ aliquot of the reaction mixture was ultra centrifuged to give a visibly yellow pellet of fibrils. These were resuspended in $200 \mu \mathrm{L}$ water before being diluted for imaging by total internal reflection fluorescence (TIRF) microscopy.

\section{Preparation of azide-functionalized GFP}

A construct of eGFP in the pOPIN_J vector was a gift from Owen Burbidge (University of Cambridge). The protein was expressed in E. coli cells and purified using nickel-nitrilotriacetic acid (Ni-NTA) beads (QIAGEN, Manchester, UK) followed by size-exclusion chromatography on a HiLoad 26/60 Superdex 75 prep-grade column (GE Healthcare, Little Chalfont, UK). Purified protein was flash-frozen and stored at $-80^{\circ} \mathrm{C}$.

The $\mathrm{N}$-terminal amine of the eGFP was converted to an azide using the protocol of Schoffelen et al. [39]. This method reliably converts $\mathrm{N}$-terminal amines to azides without modifying lysine residues. The protein was exchanged into $50 \mathrm{mM}$ Clark and Lubs buffer at $\mathrm{pH} 8.9$ using a NAP-5 column (GE Healthcare) to give a $71.8 \mu \mathrm{M}$ solution. $240 \mu \mathrm{L}$ of this was added to $227 \mu \mathrm{L}$ of $50 \mathrm{mM}$ Clark \& Lubs buffer at pH 8.9 and $33 \mu \mathrm{L}$ of a $2 \mathrm{mg} / \mathrm{mL}$ solution of imidazolyl-1-sulfonyl azide (synthesized by Yu Heng Lau, University of Cambridge, according to a literature procedure [40]). The mixture was shaken at $37^{\circ} \mathrm{C}$ overnight, and the extent of diazotization checked by mass spectrometry.

\section{Functionalization of fibrils with eGFP}

Fibrils were reacted with eGFP using a similar method to that above by adding fibrils and catalyst to the solution of azide-functionalized eGFP prepared in the previous paragraph. A control reaction was also carried out in the absence of the click catalyst mix. Again, after the reaction the fibrils were pelleted by ultracentrifugation and resuspended in water. As an additional control, the reaction was also carried out with unaggregated lyophilized peptide $(10 \mathrm{mg} / \mathrm{mL})$ instead of fibrils, with the addition of $10 \%$ acetonitrile at $37{ }^{\circ} \mathrm{C}$. As the click reaction is faster than amyloid fibril formation, taking place over a timescale of tens of minutes [34] rather than hours [41], the intention of this control was to attempt to form fibrils after the peptide had been conjugated to eGFP.

The eGFP-functionalized fibrils were imaged by TIRF microscopy using a similar method to that used for fluorescein (see below). In addition, the fluorescence polarization of free eGFP and of eGFP clicked onto fibrils was measured using an LS-55 luminescence spectrometer (Perkin-Elmer, Beaconsfield, UK). Either a $7.18 \mu \mathrm{M}$ 
solution of eGFP in Clark and Lubs buffer or a tenfold dilution of the pelleted and resuspended fibrils from the click reaction mixture were measured at $25{ }^{\circ} \mathrm{C}$ in a QS-284 quartz glass cuvette with an excitation path length of $10 \mathrm{~mm}$ and an emission path length of $2 \mathrm{~mm}$, using an excitation wavelength of $488 \mathrm{~nm}$ and an emission wavelength of $509 \mathrm{~nm}$. Quoted figures are an average of 10 measurements.

\section{TIRF microscopy}

Fibrils were diluted tenfold and a $5 \mu \mathrm{L}$ aliquot was deposited onto chambered coverglass $(80,827, \mu$-Slide, ibidi). Fibrils were allowed to settle for $10 \mathrm{~min}$ before adding $200 \mu \mathrm{L}$ PBS. Prior to imaging, the coverglass was cleaned using $1 \mathrm{M}$ potassium hydroxide for $30 \mathrm{~min}$ before washing 3 times with ultrapure water (MilliQ). Fibril samples were imaged using a 100x/1.49NA objective (UAPON100XOTIRF, Olympus) on an Olympus IX71 inverted microscope with custom built TIRF illumination. The incident angle for TIRF was controlled by laterally translating the laser focus in the back focal plane of the microscope objective. EGFP was excited using a $488 \mathrm{~nm}$ diode laser (iBeam SMART, Toptica), with detection via a 525/30 nm bandpass filter (FF01525/30, Semrock) onto an sCMOS camera (ORCA Flash 4.0, Hamamatsu). Image acquisition was controlled using Micro-Manager software [42] with 100-200 ms exposure times.

\section{Additional file}

Additional file 1. Synthesis of o-propargyl serine, image processing details and fluorescence polarization results

\section{Abbreviations}

AFM: atomic force microscopy; DIEA: N,N-diisopropylethylamine; E.coli: Escherichia coli; eGFP: enhanced Green Fluorescent Protein; HBTU: 2-(1H-benzotriazol-1-yl)-1,1,3,3-tetramethyluronium hexafluorophosphate; LC-MS: liquid chromatography mass spectrometry; PBS: phosphate buffered saline; TIRF: total internal reflection fluorescence; THPTA:Tris(3-hydroxypropyltriazolylmethyl)amine (THPTA); TTR: transthyretin.

\section{Authors' contributions}

APMG, TPJK and LSI designed the experiments. APMG performed synthesis of and characterization of fibrils and conjugation experiments. DM-V performed mass spectrometry experiments, and LJY performed TIRF microscopy on a set-up designed by LJY and CFK. APMG, LJY and DM-V wrote the paper. All authors read and approved the final manuscript.

\section{Author details}

1 Department of Pharmacology, University of Cambridge, Tennis Court Road, Cambridge CB2 1PD, UK. ${ }^{2}$ Department of Chemistry, University of Cambridge, Lensfield Road, Cambridge CB2 1EW, UK. ${ }^{3}$ Department of Chemical Engineering and Biotechnology, University of Cambridge, Philippa Fawcett Drive, Cambridge CB3 OAS, UK

\section{Acknowledgements}

This work was supported by the EPSRC Cambridge NanoDTC, EP/G037221/1 (APMG, LJY). LSI holds a Senior Fellowship from the Medical Research
Foundation. TPJK thanks the ERC, the BBSRC and the Newman Foundation for support. The authors thank Yu Heng Lau and Silvia Sonzini for help with synthesis of the peptide, and Asha Boodhun for help with mass spectrometry. CFK acknowledges funding from EPSRC, MRC, Wellcome Trust, and Infinitus China Ltd.

\section{Competing interests}

The authors declare that they have no competing interests.

\section{Availability of data}

The datasets used and/or analysed during the current study from the corresponding author on reasonable request.

\section{Consent to participate}

Consent to Participate is not applicable as this work does not report on or involve the use of any animal or human data or tissue and does not contain data from any individual person.

\section{Consent for publication}

Consent for Publication is not applicable as this work does not report on or involve the use of any animal or human data or tissue and does not contain data from any individual person.

\section{Ethics approval}

Ethics approval is not applicable as this work does not report on or involve the use of any animal or human data or tissue and does not contain data from any individual person.

\section{Publisher's Note}

Springer Nature remains neutral with regard to jurisdictional claims in published maps and institutional affiliations.

Received: 17 March 2017 Accepted: 23 September 2017

Published online: 06 October 2017

\section{References}

1. Woolfson DN. Building fibrous biomaterials from alpha-helical and collagen-like coiled-coil peptides. Biopolymers. 2010;94:118-27. doi:10.1002/ bip. 21345 .

2. Fichman G, Gazit E. Self-assembly of short peptides to form hydrogels: design of building blocks, physical properties and technological applications. Acta Biomater. 2014;10:1671-82. doi:10.1016/j.actbio.2013.08.013.

3. Li C, Born AK, Schweizer T, Zenobi-Wong M, Cerruti M, Mezzenga R. Amyloid-hydroxyapatite bone biomimetic composites. Adv Mater. 2014;26:3207-12

4. Baldwin AJ, Knowles TPJ, Tartaglia GG, Fitzpatrick AW, Devlin GL, Shammas SL, et al. Metastability of native proteins and the phenomenon of amyloid formation. J Am Chem Soc. 2011;133:14160-3.

5. Sunde M, Serpell LC, Bartlam M, Fraser PE, Pepys MB, Blake CC. Common core structure of amyloid fibrils by synchrotron X-ray diffraction. J Mol Biol. 1997;273:729-39. doi:10.1006/jmbi.1997.1348.

6. Dobson CM. Protein folding and misfolding. Nature. 2003;426:884-90.

7. Pezza JA, Villali J, Sindi SS, Serio TR. Amyloid-associated activity contributes to the severity and toxicity of a prion phenotype. Nat Commun. 2014:5:4384. doi:10.1038/ncomms5384.

8. Shewmaker F, McGlinchey RP, Wickner RB. Structural insights into functional and pathological amyloid. J Biol Chem. 2011;286:16533-40. doi:10.1074/jbc.R111.227108.

9. Chapman MR, Robinson LS, Pinkner JS, Roth R, Heuser J, Hammar M, et al. Role of Escherichia coli curli operons in directing amyloid fiber formation. Science. 2002;295:851-5. doi:10.1126/science.1067484.

10. Seviour T, Hansen SH, Yang L, Yau YH, Wang VB, Stenvang MR, et al. Functional amyloids keep quorum-sensing molecules in check. J Biol Chem. 2015:290:6457-69. doi:10.1074/jbc.M114.613810.

11. Tian P, Boomsma W, Wang Y, Otzen DE, Jensen MH, Lindorff-Larsen $K$. Structure of a functional amyloid protein subunit computed using 
sequence variation. J Am Chem Soc. 2015;137:22-5. doi:10.1021/ ja5093634.

12. Knowles TP, Fitzpatrick AW, Meehan S, Mott HR, Vendruscolo M, Dobson $\mathrm{CM}$, et al. Role of intermolecular forces in defining material properties of protein nanofibrils. Science. 2007;318:1900-3. doi:10.1126/ science.1150057.

13. Knowles TPJ, Oppenheim TW, Buell AK, Chirgadze DY, Welland ME. Nanostructured films from hierarchical self-assembly of amyloidogenic proteins. Nat Nanotechnol. 2010;5:204-7.

14. Ruggeri FS, Adamcik J, Jeong JS, Lashuel HA, Mezzenga R, Dietler G. Influence of the beta-sheet content on the mechanical properties of aggregates during amyloid fibrillization. Angew Chemie Int Ed. 2015;54:2462-6.

15. Forman CJ, Nickson AA, Anthony-Cahill SJ, Baldwin AJ, Kaggwa G, Feber $\mathrm{U}$, et al. The morphology of decorated amyloid fibers is controlled by the conformation and position of the displayed protein. ACS Nano. 2012;6:1332-46. doi:10.1021/nn204140a.

16. Forman CJ, Wang N, Yang ZY, Mowat CG, Jarvis S, Durkan C, et al. Probing the location of displayed cytochrome b562 on amyloid by scanning tunnelling microscopy. Nanotechnology. 2013;24:175102. doi:10.1088/0957-4484/24/17/175102

17. Li D, Jones EM, Sawaya MR, Furukawa H, Luo F, Ivanova M, et al. Structure-based design of functional amyloid materials. J Am Chem Soc. 2014;136(52):18044-51. doi:10.1021/ja509648u.

18. Shimanovich U, Efimov I, Mason TO, Flagmeier P, Buell AK, Gedanken A, et al. Protein microgels from amyloid fibril networks. ACS Nano. 2014; doi:10.1021/nn504869d.

19. Woolfson DN, Mahmoud ZN. More than just bare scaffolds: towards multi-component and decorated fibrous biomaterials. Chem Soc Rev. 2010;39:3464-79. doi:10.1039/c0cs00032a.

20. Simon M, Zangemeister-Wittke U, Plückthun A. Facile double-functionalization of designed ankyrin repeat proteins using click and thiol chemistries. Bioconjug Chem. 2012;23:279-86. doi:10.1021/bc200591x.

21. Nguyen DP, Lusic H, Neumann H, Kapadnis PB, Deiters A, Chin JW. Genetic encoding and labeling of aliphatic azides and alkynes in recombinant proteins via a pyrrolysyl-tRNA Synthetase/tRNA(CUA) pair and click chemistry. J Am Chem Soc. 2009;131:8720-1. doi:10.1021/ja900553w.

22. Hudalla GA, Sun T, Gasiorowski JZ, Han H, Tian YF, Chong AS, et al. Gradated assembly of multiple proteins into supramolecular nanomaterials. Nat Mater. 2014;13:829-36. doi:10.1038/nmat3998.

23. Shimanovich U, Efimov I, Mason TO, Flagmeier P, Buell AK, Gedanken $A$, et al. Protein microgels from amyloid fibril networks. ACS Nano. 2015;9:43-51

24. Rostovtsev VV, Green LG, Fokin W, Sharpless KB. A stepwise Huisgen cycloaddition process: copper(I)-catalyzed regioselective "Ligation" of azides and terminal alkynes. Angew Chem. 2002;41:2596-9. doi:10.1002/1521-3773(20020715)41:14<2596:AID-ANIE2596>3.0.CO;2-4.

25. Kolb HC, Finn MG, Sharpless KB. Click chemistry: diverse chemical function from a few good reactions. Angew Chem Int Ed. 2001;40:2004-21.
26. Moses JE, Moorhouse AD. The growing applications of click chemistry. Chem Soc Rev. 2007;36:1249-62. doi:10.1039/b613014n.

27. Agard NJ, Baskin JM, Prescher JA, Lo A, Bertozzi CR. A comparative study of bioorthogonal reactions with azides. ACS Chem Biol. 2006;1:644-8.

28. Humenik M, Scheibel T. Nanomaterial building blocks based on spider silk-oligonucleotide conjugates. ACS Nano. 2014;8:1342-9.

29. Dehn S, Castelletto V, Hamley IW, Perrier S. Altering peptide fibrillization by polymer conjugation. Biomacromol. 2012;13:2739-47. doi:10.1021/ bm3007117.

30. Fitzpatrick AWP, Debelouchina GT, Bayro MJ, Clare DK, Caporini MA, Bajaj VS, et al. Atomic structure and hierarchical assembly of a cross- $\beta$ amyloid fibril. Proc Natl Acad Sci USA. 2013;110:5468-73.

31. Johnson SM, Connelly S, Fearns C, Powers ET, Kelly JW. The transthyretin amyloidoses: from delineating the molecular mechanism of aggregation linked to pathology to a regulatory-agency-approved drug. J Mol Biol. 2012;421:185-203. doi:10.1016/j.jmb.2011.12.060.

32. Gras SL, Tickler AK, Squires AM, Devlin GL, Horton MA, Dobson CM, et al. Functionalised amyloid fibrils for roles in cell adhesion. Biomaterials. 2008;29:1553-62. doi:10.1016/j.biomaterials.2007.11.028.

33. Arpino JAJ, Rizkallah PJ, Jones DD. Crystal structure of enhanced green fluorescent protein to $1.35 \mathrm{~A}$ resolution reveals alternative conformations for Glu222. PLoS ONE. 2012;7:e47132.

34. Hong V, Presolski SI, Ma C, Finn MG. Analysis and optimization of coppercatalyzed azide-alkyne cycloaddition for bioconjugation. Angew Chem Int Ed. 2009;48:9879-83. doi:10.1002/anie.200905087.

35. Amblard M, Fehrentz J-A, Martinez J, Subra G. Methods and protocols of modern solid phase peptide synthesis. Mol Biotechnol. 2006;33:239-54. doi:10.1385/MB:33:3:239.

36. Nečas D, Klapetek P. Gwyddion: an open-source software for SPM data analysis. Open Phys. 2012;10:181-8. doi:10.2478/s11534-011-0096-2.

37. Bock VD, Hiemstra H, van Maarseveen JH. Cul-catalyzed alkyne-azide "Click" cycloadditions from a mechanistic and synthetic perspective. European J Org Chem. 2006;2006:51-68. doi:10.1002/ejoc.200500483.

38. Presolski SI, Hong VP, Finn MG. Copper-catalyzed azide-alkyne click chemistry for bioconjugation. In: Current protocols in chemical biology. Hoboken: Wiley; 2011. p. 153-62. doi:10.1002/9780470559277.ch110148.

39. Schoffelen S, van Eldijk MB, Rooijakkers B, Raijmakers R, Heck AJR, van Hest JCM. Metal-free and pH-controlled introduction of azides in proteins. Chem Sci. 2011;2:701.

40. Goddard-Borger ED, Stick RV. An efficient, inexpensive, and shelf-stable diazotransfer reagent: imidazole-1-sulfonyl azide hydrochloride. Org Lett. 2007:9:3797-800. doi:10.1021/ol701581g.

41. Bongiovanni MN, Puri D, Goldie KN, Gras SL. Noncore residues influence the kinetics of functional TTR(105-115)-based amyloid fibril assembly. J Mol Biol. 2012;421:256-69. doi:10.1016/j.jmb.2011.12.020.

42. Edelstein A, Amodaj N, Hoover K, Vale R, Stuurman N. Computer control of microscopes using $\mu$ Manager. In: Current protocols in molecular biology. Hoboken: Wiley; 2010. p. 1-22. doi:10.1002/0471142727.mb1420s92.

\section{Submit your next manuscript to BioMed Central and we will help you at every step:}

- We accept pre-submission inquiries

- Our selector tool helps you to find the most relevant journal

- We provide round the clock customer support

- Convenient online submission

- Thorough peer review

- Inclusion in PubMed and all major indexing services

- Maximum visibility for your research

Submit your manuscript at www.biomedcentral.com/submit 